\title{
Secondary prevention implantable cardioverter-defibrillator (ICD) therapy: value in octogenarians
}

\author{
Christian Hauck $^{1}$ (D) Andreas Schober ${ }^{1}$. Alexander Schober ${ }^{1}$. Sabine Fredersdorf-Hahn ${ }^{1}$. Ute Hubauer ${ }^{1}$. \\ Andreas Keyser $^{2} \cdot$ Lars Maier $^{1} \cdot$ Carsten Jungbauer $^{1} \cdot$ Ekrem Ücer $^{1}$
}

Received: 7 July 2021 / Accepted: 27 October 2021 / Published online: 9 November 2021

(c) The Author(s) 2021

\begin{abstract}
Background Implantable cardioverter-defibrillator (ICD) therapy is well established for secondary prevention, but studies on the efficacy and safety in elderly patients are still lacking. This retrospective study compared the outcome after ICD implantation between octogenarians and other age groups.

Methods Data were obtained from a local ICD registry. Patients who received ICD implantation for secondary prevention at our department were included. All-cause mortality, appropriate ICD therapy and acute adverse events requiring surgical intervention were compared between different age groups.

Results 519 patients were enrolled, 34 of whom were aged $\geq 80$ years. During the median follow-up of 35 months after ICD implantation 129 patients (annual mortality rate 5.0\%) had died, including 16 patients aged $\geq 80$ years (annual mortality rate $9.4 \%)$. The mortality rate of patients aged $\geq 80$ years was significantly higher than that of patients aged $\leq 69$ years $(p<0.001)$, but similar to that of patients aged 70-79 years. Age at the time of ICD implantation was an independent predictor of allcause mortality $(p<0.001) .29 .7 \%$ of patients had appropriate ICD therapy with no difference between age groups. Acute adverse events leading to surgical intervention were low $(n=13)$ and not age-related.

Conclusion Age is an independent predictor of mortality after ICD implantation for secondary prevention. Mortality rates did not differ significantly between octogenarians and other elderly aged 70-79 years. Appropriate ICD therapy and acute adverse events leading to surgical intervention were not age-related. Implantable cardioverter-defibrillator therapy for secondary prevention seems to be an effective and safe treatment modality in octogenarians.
\end{abstract}

Keywords Implantable cardioverter defibrillator $\cdot$ Elderly $\cdot$ Octogenarians $\cdot$ Secondary prevention $\cdot$ Mortality

\section{Introduction}

Implantation of an implantable cardioverter-defibrillator (ICD) is the current state-of-the-art therapy to reduce mortality in patients with malign ventricular arrhythmias (VA) as well in survivors of sudden cardiac death due to VA [1-4]. Because of population aging, octogenarians (patient

Carsten Jungbauer and Ekrem Ücer have contributed equally to this publication.

Christian Hauck

christian.hauck@ukr.de

1 Department of Internal Medicine II, University Medical Center Regensburg, 93042 Regensburg, Germany

2 Department of Cardiothoracic Surgery, University Medical Center Regensburg, 93042 Regensburg, Germany age $\geq 80$ years) have become a relevant patient group for an ICD therapy, but this group of patients is still underrepresented in the large ICD trials [1-4]. According to a recent German pacemaker registry report $12.3 \%$ of all ICD implantations were performed in octogenarians [5]. Because these patients often suffer from non-cardiac comorbidities leading to non-cardiac death, the benefit of ICD therapy in patients aged $\geq 80$ years is still a matter of debate [6].

The current study investigates the clinical outcome of octogenarians after ICD implantation for secondary prevention with regard to all-cause mortality, appropriate ICD therapy and device-related adverse events requiring surgical intervention. 


\section{Methods}

\section{Database}

The data of all patients, who received an ICD at our department, were entered into a database. Baseline data include clinical, echocardiographic and device parameters as well as acute adverse events after ICD implantation. The first follow-up visit took place 6 weeks after the implantation. Subsequently, patients had regular follow-up visits every 3-6 months. During each visit a device interrogation was performed by one of our physicians. The device parameters, any episodes of VA, ICD therapies and device-related complications were documented in the registry.

The ICD registry of the University Medical Center Regensburg has been approved by the institutional Ethics Committee and follows the ethical standards laid down in the 1964 Declaration of Helsinki and its later amendments.

\section{Study group}

The current study included 519 patients from the Res-IST Registry who had received an ICD for secondary prevention indication at our department between January 2005 and September 2018. Patients were divided into 6 groups according to their age at the time of ICD implantation $[\leq 59$ years $(n=202), 60-64$ years $(n=75), 65-69$ years $(n=81)$, $70-74$ years $(n=70), 75-79$ years $(n=57)$ and $\geq 80$ years $(n=34)]$.

\section{Outcomes}

The primary endpoints of the study were all-cause mortality and appropriate ICD therapy, which was defined as antitachycardia pacing (ATP) and/or ICD shock due to ventricular arrhythmias. The safety aspects of ICD implantation were also evaluated, including implantation- and device- related adverse effects such as lead dislocation, lead perforation, device-pocket hematoma, pneumothorax, hemothorax, ICD system infection and pericardial effusion requiring revision surgery during the first month after ICD implantation.

\section{Statistical analysis}

Descriptive data are presented as mean \pm standard deviation (SD), medians \pm interquartile range (IQR) or percentages. The Mann-Whitney U test was used for continuous variables and the Chi-squared test was used for ordinal variables to test statistical significance. The baseline characteristics of patients aged $<80$ years were compared to those of patients aged $\geq 80$ years. The selected endpoints were compared between the different age groups ( $\leq 59$ years, $60-64$ years,
65-69 years, 70-74 years, 75-79 years and $\geq 80$ years) according to Kaplan-Meier analysis and statistical significance was tested with the log-rank test. Furthermore, a Cox-Regression model was used to analyze the influence of age, left ventricular ejection fraction (LVEF), cardiac resynchronization therapy (CRT), ischemic heart disease (IHD), dilated cardiomyopathy (DCM), chronic kidney disease, diabetes mellitus and obesity on all-cause mortality after ICD implantation. A $p$ value of $\leq 0.05$ was considered statistically significant. For statistical analysis IBM Statistics SPSS Version 25 was used.

\section{Results}

\section{Baseline characteristics}

The baseline characteristics of the 519 patients included in the study are presented in Table 1 . Mean age was $61.2 \pm 14.5$ years and most patients were men $(80.3 \%)$. The indication for ICD implantation was ventricular fibrillation (VF) in $42.2 \%$ and ventricular tachycardia (VT) in $56.3 \%$ of patients. $57.3 \%$ of patients had ischemic heart disease, and mean LVEF was $38 \pm 14 \%$. Patients aged $\geq 80$ years had more often ischemic heart disease, permanent atrial fibrillation and chronic kidney disease as well as a lower body mass index. The rate of patients with DCM, other cardiomyopathies or channelopathies and obesity was significantly higher in the age group $<80$ years.

\section{Mortality}

During the follow-up of 35 months (IQR 11-60 months) after ICD implantation 129 (24.9\%) patients in the study group had died, 16 of whom were octogenarians. The annual mortality rate was $5.0 \%$ for the entire study group, $9.4 \%$ for octogenarians, and $4.7 \%$ for patients aged $<80$ years. According to Kaplan-Meier analysis, the mortality rate in the age group $\geq 80$ years was significantly higher than that of patients aged $<80$ years $(p<0.001)$ (Fig. 1). Patients were then divided into subgroups according to their age in 5-year steps. A further analysis of the annual mortality rates of these different age groups showed significantly lower annual mortality rates for patients aged $<70$ years than for octogenarians $[\leq 59$ years $(2.4 \% ;<0.001), 60-64$ years $(3.5 \% ; p<0.001)$, $65-69$ years $(4.9 \% ; p=0.002)]$ but no significant difference between octogenarians and patients aged $70-79$ years of age [70-74 years $(9.4 \% ; p=0.39) ; 75-79$ years $(8.1 \%$; $p=0.30)$ ] (Table 2). 
Table 1 Baseline characteristics (compared age $<80$ years and $\geq 80$ years; $p$ value $\leq 0.05$ considered statistically significant)

\begin{tabular}{|c|c|c|c|c|c|}
\hline & All $(n=519)$ & \multicolumn{2}{|c|}{$<80$ years $(n=485)$} & $\geq 80$ years $(n=34)$ & $p$ value \\
\hline Age & $61.2( \pm 14.5)$ & $59.7( \pm 13.8)$ & & $82.6( \pm 2.2)$ & $<0.001$ \\
\hline Men & $417(80.3 \%)$ & $390(80.4 \%)$ & & $27(79.4 \%)$ & 0.89 \\
\hline BMI $\left(\mathrm{kg} / \mathrm{m}^{2}\right)$ & $27.4( \pm 5.1)$ & $27.5( \pm 5.1)$ & & $25.3( \pm 3.4)$ & 0.02 \\
\hline LVEF & $38 \%( \pm 14)$ & $38 \%( \pm 14)$ & & $37 \%( \pm 9)$ & 0.28 \\
\hline ICD indication VF & $219(42.2 \%)$ & $209(43.1 \%)$ & & $10(29.4 \%)$ & 0.12 \\
\hline ICD indication VT & $292(56.3 \%)$ & $268(55.3 \%)$ & & $24(70.6 \%)$ & 0.08 \\
\hline ICD indication others ${ }^{\mathrm{a}}$ & $8(1.5 \%)$ & $8(1.6 \%)$ & & 0 & 0.45 \\
\hline Single-chamber ICD & $327(63.0 \%)$ & $305(62.9 \%)$ & & $22(64.7 \%)$ & 0.83 \\
\hline Dual-chamber ICD & $147(28.3 \%)$ & $139(28.7 \%)$ & & $8(23.5 \%)$ & 0.52 \\
\hline S-ICD & $13(2.5 \%)$ & $13(2.7 \%)$ & & 0 & 0.33 \\
\hline CRT & $32(6.2 \%)$ & $28(5.8 \%)$ & & $4(11.8 \%)$ & 0.16 \\
\hline IHD & $297(57.3 \%)$ & $272(56.1 \%)$ & & $25(73.5 \%)$ & 0.05 \\
\hline DCM & $148(28.5 \%)$ & $145(29.9 \%)$ & & $3(8.8 \%)$ & 0.01 \\
\hline Others $^{\mathrm{b}}$ & $95(18.3 \%)$ & $93(19.2 \%)$ & & $2(5.9 \%)$ & 0.05 \\
\hline History of MI & $198(38.2 \%)$ & $183(37.7 \%)$ & & $15(44.1 \%)$ & 0.74 \\
\hline Atrial fibrillation & $178(34.3 \%)$ & $159(32.8 \%)$ & & $19(55.9 \%)$ & 0.006 \\
\hline Paroxysmal AFib & $89(17.1 \%)$ & $84(17.3 \%)$ & & $5(14.7 \%)$ & 0.70 \\
\hline Persistent AFib & $26(5.0 \%)$ & $25(5.2 \%)$ & & $1(2.9 \%)$ & 0.57 \\
\hline Permanent AFib & $63(12.1 \%)$ & $50(10.3 \%)$ & & $13(38.2 \%)$ & $<0.001$ \\
\hline Diabetes & $135(26.0 \%)$ & $125(25.8 \%)$ & & $10(29.4 \%)$ & 0.64 \\
\hline Hypertension & $323(62.2 \%)$ & $298(61.4 \%)$ & & $25(73.5 \%)$ & 0.16 \\
\hline Obesity $(\mathrm{BMI} \geq 30)$ & $125(24.1 \%)$ & $122(25.2 \%)$ & & $3(8.8 \%)$ & 0.03 \\
\hline Hyperlipidemia & $267(51.4 \%)$ & $248(51.1 \%)$ & & $19(55.9 \%)$ & 0.59 \\
\hline History of stroke & $67(12.7 \%)$ & $63(12.8 \%)$ & $4(11.8 \%)$ & & 0.84 \\
\hline PAD & $54(10.4 \%)$ & $52(10.7 \%)$ & $2(5.9 \%)$ & & 0.37 \\
\hline Carotid stenosis & $23(4.4 \%)$ & $20(4.1 \%)$ & $3(8.8 \%)$ & & 0.20 \\
\hline CKD & $120(23.1 \%)$ & $107(22.1 \%)$ & $13(38.2 \%)$ & & 0.03 \\
\hline COPD & $42(8.1 \%)$ & $38(7.8 \%)$ & $4(11.8 \%)$ & & 0.42 \\
\hline ACE/AT1/ARNI & $389(75.0 \%)$ & $363(74.8 \%)$ & $26(76.5 \%)$ & & 0.83 \\
\hline Beta blocker & $417(80.3 \%)$ & $390(80.4 \%)$ & $27(79.4 \%)$ & & 0.89 \\
\hline Spironolactone & $247(47.6 \%)$ & $234(48.2 \%)$ & $13(38.2 \%)$ & & 0.26 \\
\hline Diuretics & $334(64.4 \%)$ & $309(63.7 \%)$ & $25(73.5 \%)$ & & 0.25 \\
\hline Amiodarone/Sotalol & $43(8.2 \%)$ & $39(7.9 \%)$ & $4(11.8 \%)$ & & 0.45 \\
\hline Digitalis & $47(9.1 \%)$ & $43(8.9 \%)$ & $4(11.8 \%)$ & & 0.57 \\
\hline
\end{tabular}

$B M I$ body mass index, $L V E F$ left ventricular ejection fraction, $I C D$ implantable cardioverter-defibrillator, $V F$ ventricular fibrillation, $V T$ ventricular tachycardia, $S$-ICD subcutaneous implantable cardioverter-defibrillator, $C R T$ cardiac resynchronization therapy, $I H D$ ischemic heart disease, $D C M$ dilated cardiomyopathy, $M I$ myocardial infarction, $A F i b$ atrial fibrillation, $P A D$ peripheral artery disease, $C K D$ chronic kidney disease, $C O P D$ chronic obstructive pulmonary disease

ICD indication others ${ }^{\mathrm{a}}$ : patients with an out of hospital cardiac arrest (OHCA) and high probability of a primary rhythmogenic cause though first documented rhythm was asystole, pulseless electrical activity (PEA) or sinus rhythm

Others ${ }^{\text {b: }}$ primary VF: $31(6.0 \%)$, myocarditis: 13 (2.5\%), hypertrophic (obstructive) cardiomyopathy $(\mathrm{H}(\mathrm{O})$ $\mathrm{CM}): 11$ (2.1\%), secondary cardiomyopathy: 12 (2.3\%), long-QT-syndrome: 10 (1.9\%), arrhythmogenic right ventricular dysplasia (ARVD): 6 (1.2\%), Tako Tsubo cardiomyopathy: 6 (1.2\%), Brugada syndrome: $3(0.6 \%)$, non-compaction cardiomyopathy: $2(0.4 \%)$, short-QT-syndrome: $1(0.2 \%)$

\section{Predictors of all-cause mortality}

In a multivariate Cox regression model, age at the time of ICD implantation $(p<0.001)$ as well as chronic kidney disease $(p=0.05)$ were independent predictors of all-cause mortality but not LVEF $(p=0.29)$, diabetes $(p=0.44)$, obesity $(p=0.84)$, CRT therapy $(p=0.25)$, IHD $(p=0.72)$ and DCM $(p=0.67)$ (Table 3$)$. 
Fig. 1 Survival rate of patients with an age $\geq 80$ years compared to patients with an age $<80$ years

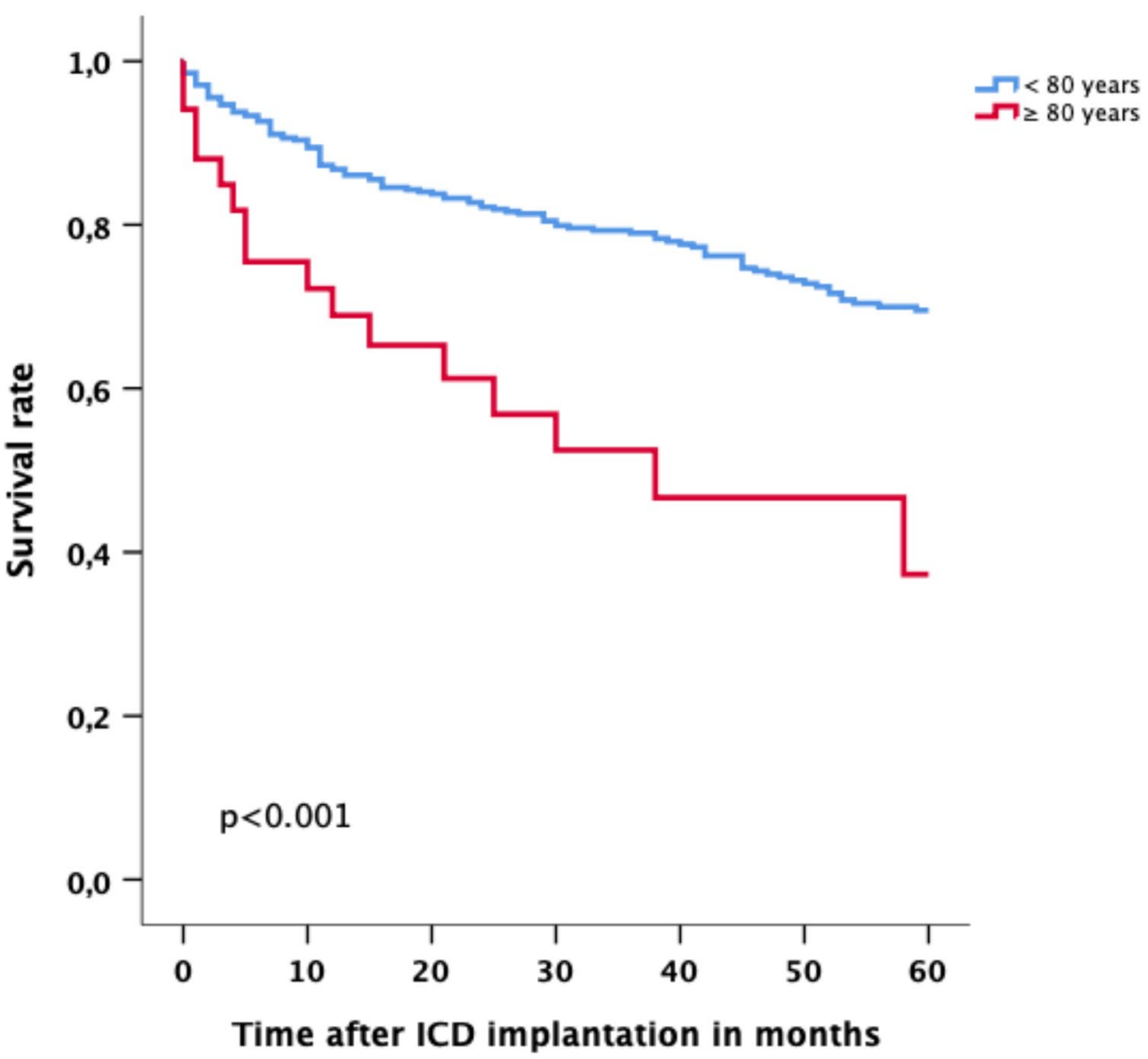

Table 2 Mortality after ICD implantation (compared to $\geq 80$ years; $p \leq 0.05$ considered statistically significant)

\begin{tabular}{lrlc}
\hline Age groups & Mortality $(129 / 519,24.9 \%)$ & $\begin{array}{l}\text { Annual } \\
\text { mortality rate } \\
(5.0 \%)\end{array}$ & $p$ value \\
\hline <80 years & $113 / 485(23.3 \%)$ & $4.7 \%$ & $<0.001$ \\
$\leq 59$ years & $24 / 202(11.9 \%)$ & $2.4 \%$ & $<0.001$ \\
60-64 years & $13 / 75(17.3 \%)$ & $3.5 \%$ & $<0.001$ \\
65-69 years & $20 / 81(24.7 \%)$ & $4.9 \%$ & 0.002 \\
$70-74$ years & $33 / 70(47.1 \%)$ & $9.4 \%$ & 0.39 \\
$75-79$ years & $23 / 57(40.4 \%)$ & $8.1 \%$ & 0.30 \\
$\geq 80$ years & $16 / 34(47.1 \%)$ & $9.4 \%$ & \\
\hline
\end{tabular}

\section{Appropriate ICD therapy due to ventricular arrhythmias}

During the follow-up, $29.7 \%$ of all patients had received appropriate ICD therapy because of ventricular arrhythmias (annual rate $5.9 \%$ ). $19.1 \%$ of patients were treated with both ATP and ICD shock or ICD shock alone and $10.6 \%$ of patients with ATP without ICD shock.
$26.5 \%$ of octogenarians received appropriate ICD therapy (annual rate 5.3\%). 20.5\% had ventricular arrhythmias and were treated with ATP and ICD shock or ICD shock alone and $6.0 \%$ with ATP without ICD shock. The rate of ICD therapy did not show any age-related difference between patients aged $\geq 80$ years and younger patients $(p=0.80)$ (Fig. 2$)$.

A comparison of the rate of ICD therapy between all age groups did not yield any significant difference between the groups $[\leq 59$ y $(31.2 \% ; p=0.70) ; 60-64$ y $(29.3 \% ; p=0.85)$; $65-69$ у $(24.7 \% ; p=0.70) ; 70-74$ y $(35.7 \% ; p=0.41)$ and $75-79$ у $(26.3 \% ; p=0.83)]$.

\section{Device-related adverse events requiring surgical intervention}

The different age groups did not significantly differ with regard to safety in the first month after ICD implantation. Event rates were very low and included lead dislocation $(n=9)$, ICD system infection $(n=2)$, pocket hematoma $(n=2)$ and hemothorax $(n=1) .1$ patient developed both lead dislocation and pocket hematoma. None of the patients in the entire study group had developed lead perforation, pneumothorax, or pericardial effusion (Table 4). 
Table 3 Results of univariate and multivariate Cox regression model

Fig. 2 Rate of appropriate ICD therapy after ICD implantation in the age group $<80$ years and $\geq 80$ years

\begin{tabular}{|c|c|c|c|c|c|c|c|c|}
\hline & \multicolumn{4}{|c|}{ Univariate analysis } & \multicolumn{4}{|c|}{ Multivariate analysis } \\
\hline & \multirow[b]{2}{*}{$p$ value } & \multirow[b]{2}{*}{ HR } & \multicolumn{2}{|l|}{$95 \%$ CI } & \multirow[b]{2}{*}{$p$ value } & \multirow[b]{2}{*}{ HR } & \multicolumn{2}{|l|}{$95 \% \mathrm{CI}$} \\
\hline & & & Lower & Upper & & & Lower & Upper \\
\hline Age & $<0.001$ & 1.05 & 1.04 & 1.07 & $<0.001$ & 1.05 & 1.02 & 1.07 \\
\hline CKD & $<0.001$ & 2.92 & 2.07 & 4.14 & 0.05 & 1.61 & 1.01 & 2.57 \\
\hline Diabetes & 0.01 & 1.67 & 1.18 & 2.41 & 0.44 & 1.21 & 0.75 & 1.93 \\
\hline IHD & 0.24 & 1.24 & 0.87 & 1.76 & 0.72 & 0.86 & 0.54 & 1.37 \\
\hline DCM & 0.54 & 0.89 & 0.60 & 1.31 & 0.67 & 1.00 & 0.43 & 2.34 \\
\hline Obesity & 0.15 & 0.73 & 0.47 & 1.12 & 0.84 & 0.89 & 0.52 & 1.52 \\
\hline LVEF & 0.27 & 0.99 & 0.97 & 1.01 & 0.29 & 0.99 & 0.97 & 1.01 \\
\hline CRT & 0.66 & 1.32 & 0.67 & 2.61 & 0.25 & 0.52 & 0.16 & 1.64 \\
\hline
\end{tabular}

$L V E F$ left ventricular ejection fraction, $C R T$ cardiac resynchronization therapy, $I H D$ ischemic heart disease, $D C M$ dilated cardiomyopathy, $C K D$ chronic kidney disease

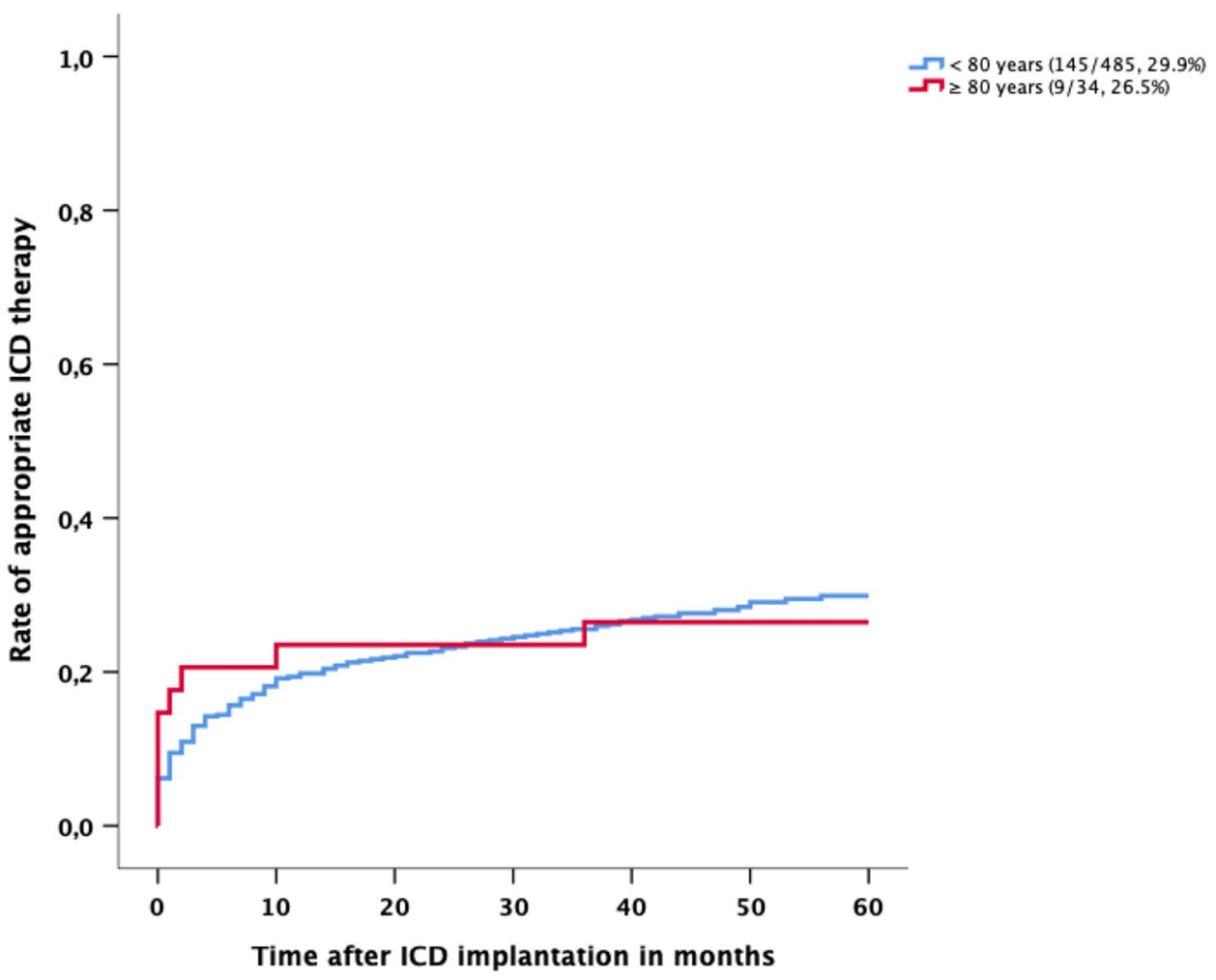

\section{Discussion}

Our single-center registry study showed a high mortality rate in octogenarians with ICD therapy for secondary prevention. Age at the time of ICD implantation was an independent risk factor for mortality during the subsequent 5 years as was chronic kidney disease. There was no age-related difference in appropriately treated ventricular arrhythmias by ICD therapy. ICD treatment did not result in any higher device-related complications leading to surgical intervention in the octogenarians than in younger
Table 4 Device-related adverse events requiring surgical intervention (compared to $\geq 80$ years; $p \leq 0.05$ considered statistically significant)

\begin{tabular}{|c|c|c|}
\hline Age groups & $\begin{array}{l}\text { Adverse events }(n=13 / 519 \text {; } \\
2.5 \%)\end{array}$ & $p$ value \\
\hline$\leq 59$ years & $4 / 202(2.0 \%)$ & 0.72 \\
\hline $60-64$ years & $3 / 75(4.0 \%)$ & 0.79 \\
\hline $65-69$ years & $2 / 81(2.5 \%)$ & 0.89 \\
\hline $70-74$ years & $0 / 70(0 \%)$ & 0.15 \\
\hline $75-79$ years & $3 / 57(5.3 \%)$ & 0.60 \\
\hline$\geq 80$ years & $1 / 34(2.9 \%)$ & \\
\hline
\end{tabular}


patient groups. Therefore, our study showed ICD therapy to be a safe treatment option for patients $\geq 80$ years.

\section{ICD therapy in elderly patients}

The effectiveness and safety of ICD therapy for secondary prevention in elderly patients is still not clear because of the underrepresentation of this patient group in the large randomized trials [1-3]. Because of population aging, however, there is a growing need for more information about the effectiveness and safety of ICD therapy in the elderly, especially in octogenarians. Previous studies have shown divergent results regarding the benefit of ICD therapy for secondary prevention in the elderly.

In a population-based registry study in Ontario, Canada, the outcome of ICD therapy for secondary prevention was compared between 159 patients aged $\geq 80$ years and patients of other age groups. Over a median follow-up of 670 days after ICD implantation, age was an independent predictor of mortality, but the number of appropriate ICD therapies, especially ICD shocks, did not differ between the different age groups [7]. Those results are very similar to our findings; the main differences to our study are the shorter follow-up duration (670 days) and the larger number of patients. A meta-analysis of three large secondary prevention trials comparing ICD to Amiodarone (AVID [3], CASH [2] and CIDS trial [1]) did not yield any significant benefit of ICD therapy over Amiodarone regarding all-cause mortality and absence of arrhythmic death in patients aged $\geq 75$ years [6]. In fact, all-cause mortality in elderly patients in the three above-mentioned studies was mainly caused by death from progressive heart failure during the first year after ICD implantation. The possible benefit of ICD therapy regarding the adequate treatment of life-threatening ventricular arrhythmias, which was not age related in our study, may become more evident over a longer lifespans.

The DANISH trial (Defibrillator Implantation in Patients with Nonischemic Systolic Heart Failure) recently described a beneficial effect of ICD therapy only in patients with nonischemic heart failure aged $<59$ years [8]. Despite the fact that the DANISH trial dealt with a completely different patient population (primary prevention patients with dilated cardiomyopathy only) and included a large number of patients with cardiac resynchronization therapy, advanced age was still a predictor of all-cause mortality.

A subgroup analysis of the three large primary prevention trials of ICD therapy (MADIT-II, SCD-Heft and COMPANION) showed a beneficial effect on mortality in older patients. A sub-study of the MADIT-II trial [9] with 204 patients aged $\geq 75$ years who had received an ICD for primary prevention showed a non-significant reduction in mortality. Similarly, a subgroup analysis of SCD-Heft [10] and COMPANION [11] showed that patients aged $>65$ years may benefit from an ICD therapy. The higher efficacy of ICD in reducing death in the elderly in primary prevention trials may be explained by the lower number of co-morbidities in these patients. Severe comorbidities such as renal failure or other systemic diseases may result in ventricular arrhythmias due to hormonal and electrolyte changes, which, in turn can result in higher mortality. In our study, age at the time of ICD implantation was an independent predictor of mortality. Patients aged $>70$ years had a similar mortality rate as octogenarians; thus, co-morbidities should be taken into account when selecting patients aged $>70$ years for ICD therapy. The all-cause annual mortality rate of $5.0 \%$ of all our patients was lower than the rates in other secondary prevention trials [1-3], which eventually may be explained by medical advances in the treatment of heart failure and coronary heart disease. During the first year after ICD implantation, ten patients in the octogenarian group died resulting in a rather high one-year mortality rate of $29.4 \%$. This shows, that in a real-world clinical setting, it is obviously difficult to assess life expectancy correctly especially in elderly patients. This is an important issue as current guidelines recommend ICD therapy for secondary prevention only for patients, who are expected to survive for more than 1 year with good functional status and quality of life. Patients with serious comorbidities, who are unlikely to survive more than 1 year, should not receive an ICD therapy [12]. Therefore, one must be cautious when evaluating elderly patients for ICD implantation and a screening for comorbidities that are limiting life expectancy to less than 1 year should be made by a multidisciplinary team approach. On the other side, the 1-year mortality rate was also high in patients aged $70-74$ years $(22.9 \%)$ and in patients aged 75-79 years (21.2\%). A possible explanation might be, that ventricular arrhythmia, which are the reason for secondary prevention ICD implantation, can be an indicator for a progress of an underlying cardiovascular disease, which can be an important limiting factor for life expectancy in older patients. Besides, the possibility that the ICD can be deactivated should be discussed as a part of the patient's informed consent for ICD implantation. For example, ICD deactivation in patients with a terminal illness may be ethically permissible to avoid painful ICD shocks [13].

Over 5 years $29.7 \%$ of our patients had undergone appropriate ICD therapy. This rate is lower than the rates in other ICD trials [1-3, 7], which may be a result of novel ICD programming strategies with longer detection times and higher cut-off rates [14]. No age-related difference could be seen for appropriate ICD therapy, proving the effectiveness of ICD therapy in treating ventricular arrhythmias in the elderly, which was comparable to other studies [7]. 
The number of device-related adverse events requiring surgical intervention was low across all age groups, so that the implantation procedure itself does not seem to involve any increased risk in elderly patients.

In our study the use of a single-lead ICD was rather high (63\%), while CRT devices were implanted in only $6.2 \%$ of our patients. One possible explanation might be, that the mean LVEF in our study group was 38\% and the current guidelines recommend CRT for patients with a left bundle branch block and a LVEF $\leq 35 \%$ [15]. Moreover, our study included patients who had received an ICD at our department from January 2005. At that time CRT was not as well established as it is today.

If elderly patients are eligible for a CRT, it is important to discuss whether one should implant a CRT-P or a CRT-D. Because the trials, which have investigated this topic, have included only patients with a primary prevention indication $[8,11]$, no scientific data exist for CRT-P for patients with a secondary prevention indication. It is worth considering, whether the potential rhythm stabilizing effect of resynchronization therapy might be a relevant therapeutic concept in octogenarians. But as scientific data are missing and ICD has been proven to reduce the risk of arrhythmic death, the current guidelines recommend a CRT-D for patients who are eligible for CRT and have a secondary prevention indication for ICD therapy $[12,15]$.

The strength of the current study compared to already existing scientific data is the long follow-up with a median of 35 months. The large scale of clinical baseline characteristics in our registry enables the identification of confounders that may influence the outcome after ICD implantation in elderly patients. Outcome after ICD implantation may be influenced by significantly more frequent concomitant diseases in patients aged $\geq 80$ years. Our study included a real-life cohort; therefore, it is possible that older patients, especially octogenarians, who were eligible for ICD therapy were more carefully selected with regard to concomitant diseases and their general health status than younger patients. This selection indicates that for octogenarians comorbidities, life expectancy, the general health status, and patient preferences need to be individually evaluated before a decision for or against an ICD therapy can be made. However, larger prospective randomized controlled trials are warranted to test the benefit of ICD therapy for secondary prevention in patients aged $\geq 80$ years.

\section{Limitations}

Our study group of octogenarians was rather small; in the absence of larger studies, our data may still be useful for evaluating the value of ICD therapy in elderly patients. The retrospective non-randomized study design includes the risk of selection bias because different factors that might have played a role in the decision process for or against an ICD therapy in certain patients cannot be evaluated retrospectively. We included patients over a period of 13 years, during which the advances in heart failure therapy, therapy for IHD, and advancement in ICD programming might have influenced patient outcome. There was also no significant difference in the drug therapy for heart failure, which otherwise might have affected outcome. Furthermore, we had no control group of older patients who did not receive ICD therapy or were treated with antiarrhythmic therapy; for this reason, we do not know if other less invasive strategies may also be effective in elderly patients. Moreover, we cannot provide data about the cause of death because this information was not collected as part of the ICD registry. Finally, this study was a single-center study; thus, we do not know if our results can be generalized for other medical centers, which may have other strategies for selecting patients eligible for ICD therapy or may use other ICD programming to treat ventricular arrhythmias.

\section{Conclusion}

This single-center registry study showed that age at the time of ICD implantation is an independent risk factor for allcause mortality in patients with ventricular arrhythmia who receive ICD therapy for secondary prevention. On the other hand, the rate of appropriately delivered ICD therapy to treat ventricular arrhythmias and the number of adverse events leading to revision surgery did not show any age-related differences. In summary, ICD therapy for secondary prevention seems to be an effective and safe therapy in elderly patients including octogenarians, who have higher all-cause mortality rates than younger patients due to comorbidities.

Supplementary Information The online version contains supplementary material available at https://doi.org/10.1007/s40520-021-02019-2.

Author contributions All authors contributed to the design and implementation of the research. $\mathrm{CH}$ and $\mathrm{CJ}$ contributed to the analysis of the results. $\mathrm{CH}$ wrote the manuscript with input from $\mathrm{CJ}$ and EÜ.

Funding Open Access funding enabled and organized by Projekt DEAL. None.

Availability of data and material Available from the corresponding author upon request.

\section{Declarations}

Conflict of interest The authors declare that they have no conflict of interest. 
Ethical approval Approved by the institutional Ethics Committee.

Consent to participate Informed consent signed by all participants.

Consent for publication Informed consent signed by all participants.

Open Access This article is licensed under a Creative Commons Attribution 4.0 International License, which permits use, sharing, adaptation, distribution and reproduction in any medium or format, as long as you give appropriate credit to the original author(s) and the source, provide a link to the Creative Commons licence, and indicate if changes were made. The images or other third party material in this article are included in the article's Creative Commons licence, unless indicated otherwise in a credit line to the material. If material is not included in the article's Creative Commons licence and your intended use is not permitted by statutory regulation or exceeds the permitted use, you will need to obtain permission directly from the copyright holder. To view a copy of this licence, visit http://creativecommons.org/licenses/by/4.0/.

\section{References}

1. Connolly SJ, Gent M, Roberts RS et al (2000) Canadian implantable defibrillator study (CIDS): a randomized trial of the implantable cardioverter defibrillator against amiodarone. Circulation 101:1297-1302. https://doi.org/10.1161/01.cir.101.11.1297

2. Kuck KH, Cappato R, Siebels J et al (2000) Randomized comparison of antiarrhythmic drug therapy with implantable defibrillators in patients resuscitated from cardiac arrest: the Cardiac Arrest Study Hamburg (CASH). Circulation 102:748-754. https://doi. org/10.1161/01.cir.102.7.748

3. Investigators, Antiarrhythmics versus Implantable Defibrillators (AVID) (1997) A comparison of antiarrhythmic-drug therapy with implantable defibrillators in patients resuscitated from near-fatal ventricular arrhythmias. N Engl J Med 337:1576-1583. https:// doi.org/10.1056/nejm199711273372202

4. Connolly SJ, Hallstrom AP, Cappato R et al (2000) Meta-analysis of the implantable cardioverter defibrillator secondary prevention trials. AVID, CASH and CIDS studies. Antiarrhythmics vs Implantable Defibrillator study. Cardiac Arrest Study Hamburg . Canadian Implantable Defibrillator Study. Eur Heart J 21:20712078. https://doi.org/10.1053/euhj.2000.2476

5. Gesundheitswesen, Fachgruppe Herzschrittmacher und DefibrillatorenbeimIQTIG-Institut für Qualitätsicherung und Transparenzim (2017) Jahresbericht 2017 des Deutschen Herzschrittmacher-und Defibrillatorregister-Teil 2 Implantierbare Cardioverter-Defibrillatoren (ICD)
6. Healey JS, Hallstrom AP, Kuck KH et al (2007) Role of the implantable defibrillator among elderly patients with a history of life-threatening ventricular arrhythmias. Eur Heart J 28:17461749. https://doi.org/10.1093/eurheartj/ehl438

7. Yung D, Birnie D, Dorian P et al (2013) Survival after implantable cardioverter-defibrillator implantation in the elderly. Circulation 127:2383-2392. https://doi.org/10.1161/circulationaha.113. 001442

8. Køber L, Thune JJ, Nielsen JC et al (2016) Defibrillator implantation in patients with nonischemic systolic heart failure. N Engl J Med 375:1221-1230. https://doi.org/10.1056/nejmoa1608029

9. Huang DT, Sesselberg HW, McNitt S et al (2007) Improved survival associated with prophylactic implantable defibrillators in elderly patients with prior myocardial infarction and depressed ventricular function: a MADIT-II substudy. J Cardiovasc Electrophysiol 18:833-838. https://doi.org/10.1111/j.1540-8167.2007. 00857.x

10. Bardy GH, Lee KL, Mark DB et al (2005) Amiodarone or an implantable cardioverter-defibrillator for congestive heart failure. N Engl J Med 352:225-237. https://doi.org/10.1056/nejmoa0433 99

11. Bristow MR, Saxon LA, Boehmer J et al (2004) Cardiac-resynchronization therapy with or without an implantable defibrillator in advanced chronic heart failure. N Engl J Med 350:2140-2150. https://doi.org/10.1056/nejmoa032423

12. McDonagh T, Metra M, Adamo M et al (2021) 2021 ESC Guidelines for the diagnosis and treatment of acute and chronic heart failure. Eur Heart J 42:3599-3726. https://doi.org/10.1093/eurhe artj/ehab368

13. Padeletti L, Arnar DO, Boncinelli L et al (2010) EHRA Expert Consesus Statement on the management of cardiovascular implantable electronic devices in patients nearing end of life or requesting withdrawal of therapy. Europace 12:1480-1489. https://doi.org/10.1093/europace/euq275

14. Schober AL, Schober AD, Hubauer U et al (2021) Novel implantable cardioverter defibrillator programming with high-rate cutoff, long detection intervals and multiple anti-tachycardia pacing reduces mortality. Circ J 85:291-299. https://doi.org/10.1253/ circj.CJ-20-0940

15. Glikson M, Nielsen JC, Kronborg MB et al (2021) 2021 ESC Guidelines on cardiac pacing and cardiac resynchronization therapy. Eur Heart J 42:3427-3520. https://doi.org/10.1093/eurheartj/ ehab364

Publisher's Note Springer Nature remains neutral with regard to jurisdictional claims in published maps and institutional affiliations. 